\title{
Membrane Sunspace for Old Buildings Refurbishment: Environmental Impact, Economic and Building Technology's Comparison to Conventional Solutions
}

\author{
Mónica Macieira ${ }^{1}$, Paulo Mendonça ${ }^{1}$ and João Miranda Guedes ${ }^{2}$ \\ ${ }^{1}$ Lab2pt, School of Architecture, University of Minho, 4800-058 Guimarães, Portugal \\ ${ }^{2}$ Construct, Faculty of Civil Engineering, University of Porto, 4200-465 Porto, Portugal
}

\begin{abstract}
This study presents a state of the art and design proposal for membrane sunspaces, as alternative to conventional ones, in glass, commonly used in the functional refurbishment of old buildings. Sunspaces are passive solar systems that can be easily integrated in existing buildings. Enclosing balconies with glazing has an impact on existing building functional performance (useful area, thermal performance and acoustic improvement) and it may even postpone the renovation need of the intervened building. However, inevitably, many of old buildings are located in areas with access restrictions and other physical constraints on the movement of materials, components and equipment - that limits its construction and maintenance processes and thus demand for alternative solutions. Glass is being applied in all types of sunspaces, so architects and engineers take for granted that it has to be inevitably used. However, a major weakness of glass is its weight and cost, specially associated with installation complexity, framing systems and accessories needed. The fact that membrane requires less substructure, changes the architectural approach - giving more freedom to design options. Membrane construction technology and installation process could be a practical alternative to traditional construction methods for closing balconies in old buildings. For this research, a full-scale Membrane Alternative Sunspace prototype was implemented into an old building (taken as case study) to evaluate the real construction process aspects and compare it with the common glazed solutions. Results were examined from an environmental, economic and building technology's point of view - regarding production, construction and maintenance phases.
\end{abstract}

\section{Introduction}

The main aim of the present paper is to compare the construction, environmental and economic benefits of sunspaces in membrane (regarding constructive and maintenance aspects) attached to buildings. Considering its lightness, resilience and flexibility, membranes are becoming common solutions in specific contexts of existing buildings' refurbishment [1]. A few millimetres membrane can be a self-supporting material and a selective sunlight filter capable of absorbing, or reflecting the ultraviolet, or infrared light whenever needed.

Providing balconies with glazing has an impact on existing buildings' functional performance, as concluded by Mendonça, Aelenei et al and Hilliaho [2, 3, 4], maximizing useful area and thermal and acoustic performance. According Mattila [5], providing balconies with transparent closing solutions has an impact on the general condition of the building as it may even postpone the balconies renovation need in the building from six to ten years. The effect of closing balcony on the maintenance period of balconies has been studied from
1998 by J. Mattila, who developed a device and measuring method that can monitor the progress of balcony and building deterioration caused by the weather. Mattila [5] concludes that balcony glazing decreases the need for maintenance of building structures and coatings in both new and refurbished buildings. If the balconies of a building that is to be refurbished are subject to weathering, balcony glazing can help to extend their service life.

\subsection{Reference sunspace's building technologies - traditional, conventional and contemporary sunspaces}

In Portugal, the integration of sunspaces in the initial architectural design phase is scarce. The reason for this is related with the fact that summer in Portugal is warm and winter is not severe. However, sunspaces appear frequently to extent useful area and as solar passive additions to existing buildings; according Gonçalves et al [6], sunspaces in Portugal present the following common features: single south oriented glazing and high glazing to 
floor surface ratio (between 60\% and 250\%). Some traditional, conventional and contemporary examples are presented on Figure 1.

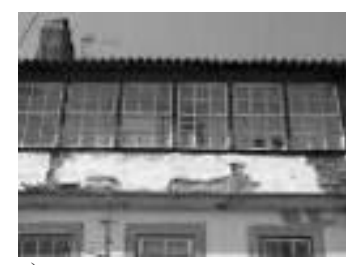

a)

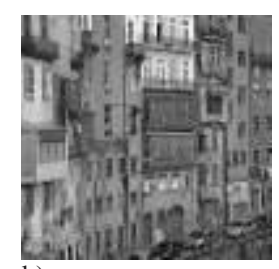

b)

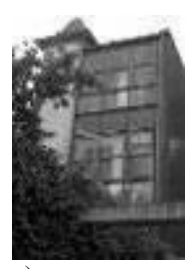

c)
Figure 1. Examples of glazed closed balconies performing as sunspaces in Portuguese old houses: a) traditional; b) mix of traditional and conventional; c) contemporary.

\section{Membrane Alternative Sunspace (MAS)}

This research deals with the use of transparent membrane screens to close existing balconies to perform as sunspaces, as an alternative to conventional glazing sunspaces, a solution commonly used in the functional refurbishment of old buildings. In particular, membrane building technologies could be preferred to conventional glass ones when lightweight and flexibility are special requirements.

In this study, two membranes with equivalent glass thermal and optical properties were selected (Table 1) clear PVC and ETFE foils. In addition to its thermooptical performance, ETFE foil is highly resistant to chemical wear and has excellent repellent properties, which means that dirt does not adhere easily and maintenance will be minimal making the product an ideal choice to use within building design. There are ETFE membrane constructions that have more than 30 years old without degradation or reduction of it mechanical properties. The ETFE foil allows the passage of the whole light spectrum, while maintaining good thermal insulation (when applied on inflatable or encapsulated systems). Selected membranes can also be designed to incorporate fritting or colouring, so that the sun light can be optimized for both the aesthetic and thermal performance. In the solution under study it was decided to apply a translucent pattern at the lower part of the facade (in a horizontal band with $1.20 \mathrm{~m}$ height) in order to offer users privacy (Figure 3c).

Table 1. Relevant properties of some transparent materials (adapted from [7])

\begin{tabular}{|c|c|c|c|c|c|c|}
\hline $\begin{array}{l}\text { Material } \\
\text { /thick } \\
(\mathrm{mm})\end{array}$ & $\begin{array}{r}\text { T vis } \\
\text { direct } \\
(\%) \\
\end{array}$ & $\begin{array}{r}\text { Tsol } \\
\text { direct } \\
(\%) \\
\end{array}$ & $\begin{array}{r}\mathbf{U} \\
\text { value } \\
\mathrm{W} /\left(\mathrm{m}^{2}{ }^{\circ} \mathrm{C}\right) \\
\end{array}$ & $\begin{array}{r}\mathbf{G} \\
\text { value }\end{array}$ & $\begin{array}{r}\text { Rsol } \\
\text { direct } \\
(\%) \\
\end{array}$ & $\begin{array}{r}\mathrm{E} \\
\text { normal }\end{array}$ \\
\hline Glass/ 6 & 85 & 90 & 6.5 & 0.87 & 8 & 0.90 \\
\hline $\begin{array}{l}\text { Glass } \\
6(10) 6\end{array}$ & 70 & 81 & 3.3 & 0.65 & 15 & _ \\
\hline $\begin{array}{l}\text { PVC } \\
\text { foil/ } 1\end{array}$ & 85 & 85 & 5.6 & 0.84 & 4 & 0.95 \\
\hline $\begin{array}{l}\text { ETFE } \\
\text { foil/ } 0.2\end{array}$ & 95 & 84 & 3.0 & 0.85 & 4 & 0.83 \\
\hline
\end{tabular}

Legend: Tvis (visual light transmission); Tsol (solar light transmission); Rsol (solar reflectance); E normal (normal emissivity, $\mathbf{T}=\mathbf{3 0 0 K}$ ).

The two membranes, PVC and ETFE, were included in two MAS techniques, referred to MAS 1 and MAS 2, respectively: the first was implemented in a real case study and the second corresponds to a solution with same material durability as glass and equivalent openable/ operational system - sliding/foldable. Both will be detailed in the next section.

\subsection{Concept and design}

\subsubsection{Single MAS in roller system (MAS 1)}

Membrane Alternative Sunspace building technology, named MAS 1, is constituted by a single clear PVC foil roller blind with lateral guides and detachable sealing and insulation, including a zip with a snap fastening system, in order to hermetically close the sunspace area, protecting it from wind and rain.

As a passive solar system, sunspaces captures sun heat to release it during periods when there is no solar radiation, in order to keep a comfortable interior space temperature. Combined with existent connection doors sunspaces can be opened to allow heat to penetrate into the adjacent compartment by convection, if energy savings are envisaged at heating season (Figure 2a). At cooling season, MAS 1 can be completely open during all day/ night time; depending on the climatic zone, an opaque/reflective membrane can be added to serve as a vertical shade (with adjustable height) (Figure 2b).

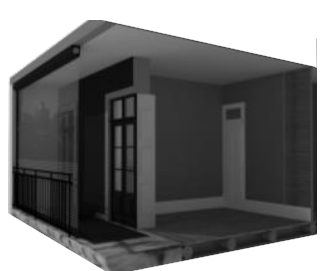

(a) closed

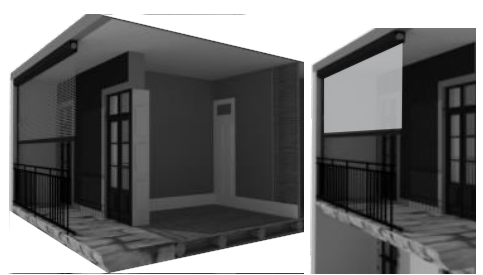

(b) open (adjustable until 95\%)
Figure 21. MAS1 in the daytime period in the heating (a) and cooling (b) season.

\subsubsection{Double MAS in sliding system (MAS 2)}

Double MAS building technology, named MAS 2, is constituted by ETFE membrane panels in which an aluminium frame is encapsulated in a double ETFE foil, through thermal contraction and welding process (taking advantage of membrane's dimensional reduction to create tension along the aluminium frame (Figure 3a)). This system allows membrane tensioning without the need to inflate the panel (patented modular panels system [8] (Figure $3 b)$ ). Frames can be easily mounted into support structures and secured using simple capping strips/ brackets similar to glass mounting. Different geometrical frames can be encapsulated, facilitating any number of configurations. In this way, MAS 2 (Figure 3c), when compared to its equivalent double glazing sunspace solution, benefits from the use of a lighter and less brittle material with superior thermo-optic properties. The benefits of using ETFE membrane panels for architectural purposes are several: (1) allows design customization - panels can be fitted together to form several configurations; (2) allows for quick and easy 
construction without the need for specialized hand labour or equipment, reducing costs and building time; (3) can be easily repaired or replaced when damaged; (4) there is no risk of structure failure if it is punctured, since the ETFE membrane is tensioned through panel frame and not by using air inflatable techniques.
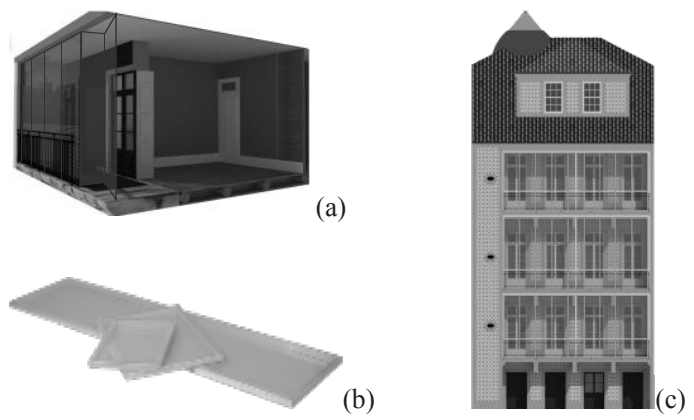

Figure 3.2 (a) MAS 2 applied to close a balcony of an old house; (b) dimensional variety of modular ETFE encapsulated panels [8]; (c) backyard façade with MAS 2.

\subsection{Experimental tests with MAS 1 prototype applied in an old building}

In order to test the feasibility of the MAS technology, a full-scale MAS 1 prototype, much less expensive than MAS 2, was built and applied to an old building, to evaluate in situ its construction process. The building taken as case study is a XIX ${ }^{\text {th }}$ century Porto's bourgeois house, with granite stone masonry structural walls, wood pavements and roof structures, and light framed timber partition walls. Figure 5 presents the MAS 1 prototype's details and Figure 4 its full-scale assembly.

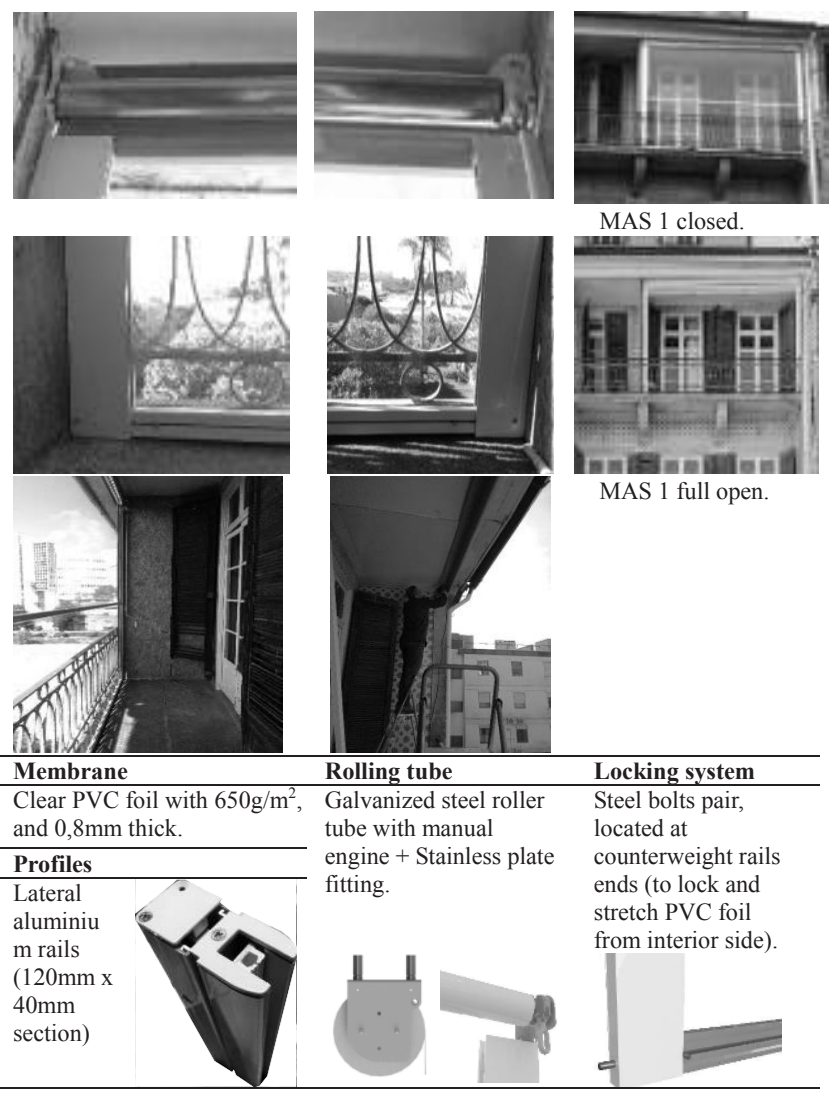

Figure 4. MAS 1 full scale prototype's components.
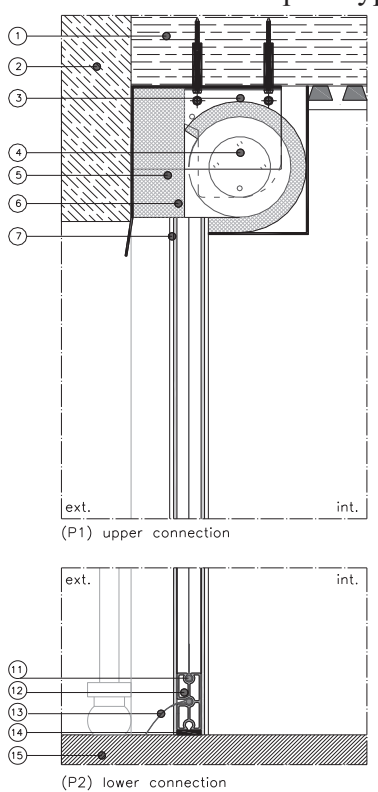

Legend:

1. Existent wood beam

2. Existent wood outline

3. Fitting clip

4. Rolling tube

5. Dripper (galvanized and bent sheet)

6. Rolling's lockbox

7. Lateral guide profile

8. Plush sealing

9. Detachable insulation

10. Clear PVC foil

11. Neoprene cord $(\varnothing 6 \mathrm{~mm})$

12. Counterweight rail for

membrane's stretch

13. PVC foil dripper welded to the vertical clear PVC foil

14. Neoprene layer (5 $10 \mathrm{~mm}$ thick)

15. Stone slab

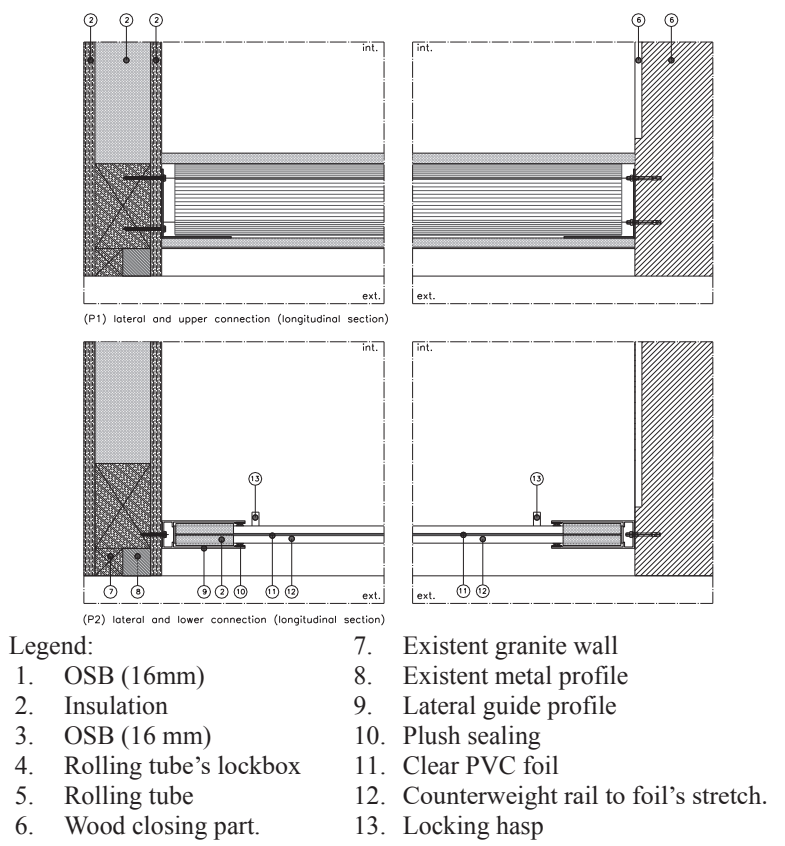

Figure 5. MAS 1 constructive details: (A) transversal and (B) longitudinal sections. Note: all connections are mechanical and easily detachable.

\section{Comparative analysis}

To attain the goal of this research, i.e. to determine if membrane building technologies could be preferred to conventional glazing ones when applied to functional refurbishment contexts, six sunspace solutions are examined regarding its global efficiency performance. In particular, they will be analysed in economic, environmental and building technology terms - regarding production, transport, construction, maintenance and end of life phases.

In the present research, sunspace is considered as a horizontal extension of an existing old building, on its backyard facade (Figure 6), to achieve more useful space area; the sunspace's height was considered to be similar 
to that of the existing adjacent rooms. Six types of sunspaces are analysed (Figure 6): Traditional sunspace (TS) with wooden frame glass windows and opaque area made off wattle and daub system covered with corrugated metal sheets; a Conventional sunspace (CS) composed by single glass with aluminium frames and opaque single brick wall; Contemporary sunspace 2 (ContS 2) with full double glass aluminium frame facade; Contemporary sunspace 1 (ContS 1) with single full glass façade, only with top and bottom horizontal aluminium profiles; Membrane Alternative Sunspace (MAS 1) with a transparent PVC single foil roller clear; and Membrane Alternative Sunspace with sliding's double ETFE foil panels (MAS 2) with encapsulated aluminium frame (ETFE foil 100\% transparent at upper part and $70 \%$ transparent at lower part). In order to achieve occupant's privacy, it is possible to add a screen (open mesh factor higher than $30 \%$ ) in each sunspace design without compromising significantly the thermal performance.

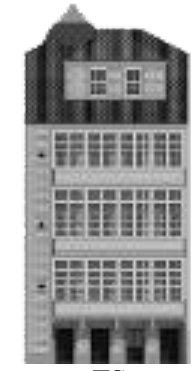

TS

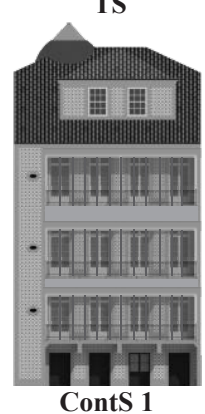

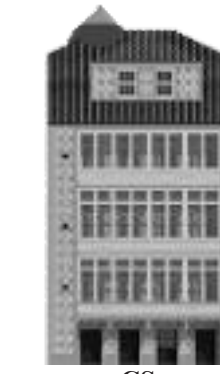

CS

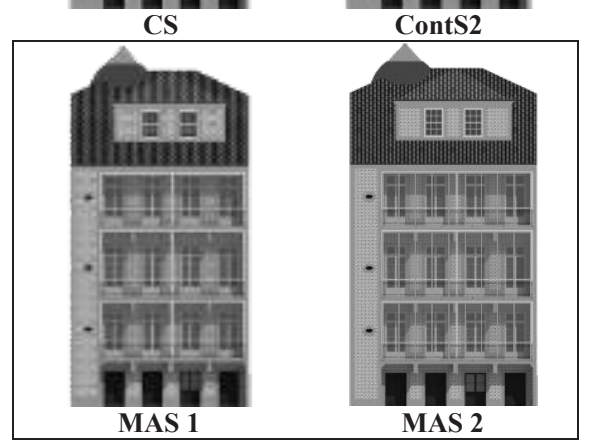

Figure 6. Case study building with reference (traditional, conventional and contemporary) and alternative sunspace design options.

\subsection{Constructive/ design aspects}

The main characteristics of sunspace design options are presented at Table 2. Solutions with lighter materials, as MAS 1 and 2, increase openable sunspace area (relevant for cooling season's needs) (Figure 7).

Table 2. Characterization of sunspace design options in analysis applied to a $100 \mathrm{~m}^{2}$ facade.

\begin{tabular}{|c|c|c|c|c|c|c|}
\hline Designation: & TS & $\mathrm{CS}$ & ContS 2 & ContS 1 & MAS 1 & MAS 2 \\
\hline $\begin{array}{l}\text { Frame } \\
\text { material }\end{array}$ & $\begin{array}{r}\text { Woo } \\
\mathrm{d}\end{array}$ & $\mathrm{AL}$ & $\mathrm{AL}$ & $\mathrm{AL}$ & $\mathrm{AL}$ & $\mathrm{AL}$ \\
\hline $\begin{array}{l}\text { Transparent } \\
\text { Material/ } \\
\text { thick }(\mathbf{m m})\end{array}$ & $\begin{array}{r}\text { Glass } \\
3\end{array}$ & $\begin{array}{r}\text { Glass } \\
6\end{array}$ & $\begin{array}{r}\text { Glass } \\
4(16) 4\end{array}$ & $\begin{array}{r}\text { Glass } \\
10\end{array}$ & $\begin{array}{r}\text { PVC foil } \\
0.8\end{array}$ & $\begin{array}{r}\text { ETFE foil } \\
0.25 \\
(30) 0.25\end{array}$ \\
\hline $\begin{array}{l}\text { Transparent } \\
\text { Area (\%) }\end{array}$ & 60 & 60 & 80 & 80 & 95 & 95 \\
\hline Opaque area & $40 \%$ & $40 \%$ & $20 \%$ & $20 \%$ & $5 \%$ & $5 \%$ \\
\hline
\end{tabular}

\begin{tabular}{|c|c|c|c|c|c|c|}
\hline $\begin{array}{l}\text { Transparent } \\
\text { operable area }\end{array}$ & $30 \%$ & $50 \%$ & $50 \%$ & $75 \%$ & $95 \%$ & $85 \%$ \\
\hline $\begin{array}{l}\text { Self-weight } \\
\left(\mathrm{kg} / \mathrm{m}^{2}\right)\end{array}$ & 46 & 95 & 19 & 22 & 1,9 & 1,8 \\
\hline Glass & 7.5 & 15.0 & 20.0 & 25.0 & - & - \\
\hline Membrane & - & - & - & - & $1,16-$ & 0.86 \\
\hline Designation: & TS & $\mathrm{CS}$ & ContS 2 & ContS 1 & MAS 1 & MAS 2 \\
\hline $\begin{array}{l}\text { U value } \\
\left(\mathrm{W} /\left(\mathrm{m} 2 .{ }^{\circ} \mathrm{C}\right)\right)\end{array}$ & 5.1 & 6.5 & 3.3 & 5.0 & $5.6^{5}$ & $3.0^{5}$ \\
\hline $\begin{array}{l}\text { Durability of } \\
\text { transparent } \\
\text { material } \\
\text { (years) }\end{array}$ & +60 & +60 & +60 & +60 & 30 & 60 \\
\hline $\begin{array}{l}\text { Maintenance } \\
\text { Period (years) }\end{array}$ & $\begin{array}{c}10 \\
\text { Clean } \\
\end{array}$ & $\begin{array}{r}10 \\
\text { Clean. }\end{array}$ & $\begin{array}{r}10 \\
\text { Clean. }\end{array}$ & $\begin{array}{r}10 \\
\text { Clean. }\end{array}$ & $\begin{array}{r}30 \\
\text { replace }\end{array}$ & $\begin{array}{r}\text { Self- } \\
\text { cleaning }\end{array}$ \\
\hline $\begin{array}{l}\text { Constructive } \\
\text { aspects - } \\
\text { limitations and } \\
\text { advantages }\end{array}$ & $*$ & $*$ & $*$ & $* *$ & $* * *$ & $* * * *$ \\
\hline
\end{tabular}

Notes: AL (aluminium); * Operable glass pane width $\leq 80 \mathrm{~cm} ; * *$ Height limited to until $3 \mathrm{~m}$; minimum thick $=10 \mathrm{~mm}$; panel width $\leq 80 \mathrm{~cm} ; * * *$ Width $\leq 4 \mathrm{~m}$; unlimited height; horizontal bracing each $1.2 \mathrm{~m} ; * * * *$ Width $\leq 1.2 \mathrm{~m}$; height $\leq 8 \mathrm{~m}$; allows curve forms.

\subsubsection{Weight}

Glass is being applied in all types of sunspaces, so architects and engineers take for granted that it is the material to be used. However, a major weakness of glass is its weight, (Figure 7) especially when associated with installation, framing systems and accessories. One of the most important properties of transparent membranes is its reduced self-weight - achieved due to its minimal thickness and density - when compared with that of glazing materials of equivalent thermal, optical and structural performance (applied at non load bearing elements) (Figure 7).

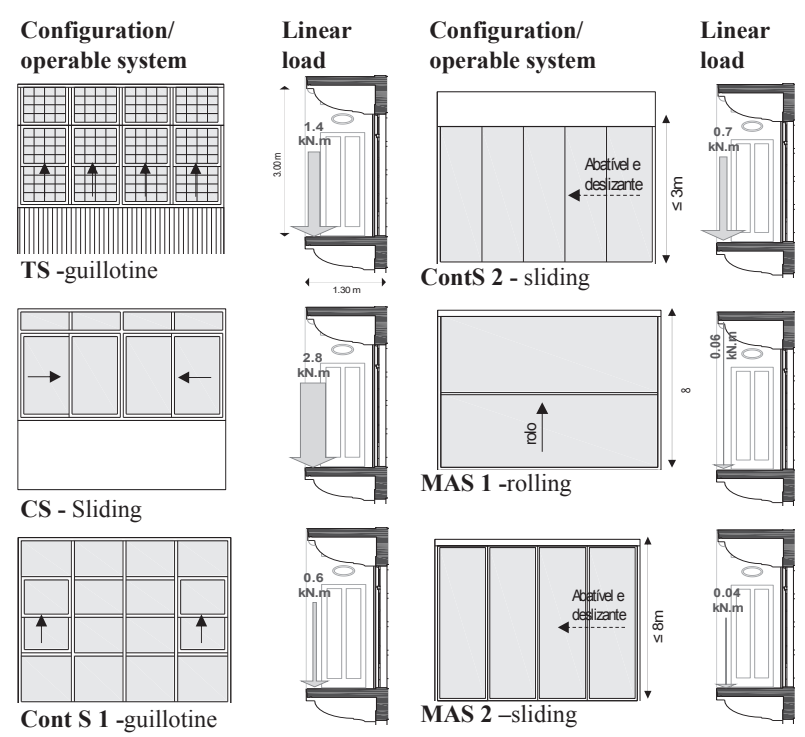

Figure 7. Transparent envelope configurations and operations and respective linear load applied at the extremity of the stone slab.

\subsubsection{Installation process - building integration- construction process improvement}

Regarding the presented reference sunspace's solutions, it is found that lighter sunspace alternatives are necessary to reduce overload on balconies, and more economic alternatives to reduce assembly costs associated with 
auxiliary equipment and assembly time. Especially in urban areas, some of which present difficult access conditions, such as in the historical centres, where the use of lighter materials reduces transport and lifting difficulties.

MAS are easy assembling and detachable/ reversible solutions. When combined with structural efficiency, resulted from membrane material's use in pure tension to resist horizontal applied loads, its low weight allows larger spans and reduces, or even eliminates, the need for secondary support structures, with consequent impact on the weight of primary structures (leading to lighter frames) (Table 2) and the energy required to manufacture, transport and installation.

MAS constitute a light clear membrane building technology to close existent balconies - to perform as sunspace with $95 \%$ operable and adjustable height shading/ ventilation for summer design option. when compared with other sunspace design options (Table 3 and Figure 8), MAS 1 and MAS 2 are the easiest and efficient solutions to employ at building refurbishments, due to the easy which it can be integrated into the existing building structure.

Table 3. Installation aspects of $100 \mathrm{~m}^{2}$ façade area of sunspace design options (based on experimental prototype assembling and [9] data).

\begin{tabular}{|lrrr|}
\hline $\begin{array}{l}\text { Design } \\
\text { options }\end{array}$ & $\begin{array}{r}\text { Estimated } \\
\text { construction } \\
\text { time }\end{array}$ & $\begin{array}{r}\text { Number } \\
\text { of } \\
\text { workers }\end{array}$ & $\begin{array}{r}\text { Auxiliary } \\
\text { equipment }\end{array}$ \\
\hline TS & $52 \mathrm{~h}$ & 4 & no \\
CS & $52 \mathrm{~h}$ & 4 & no \\
ContS 2 & $24 \mathrm{~h}$ & 4 & Glass lifting \\
ContS 1 & $24 \mathrm{~h}$ & 4 & Glass lifting \\
MAS 1 & $6 \mathrm{~h}$ & 2 & no \\
MAS 2 & $12 \mathrm{~h}$ & 2 & no \\
\hline
\end{tabular}

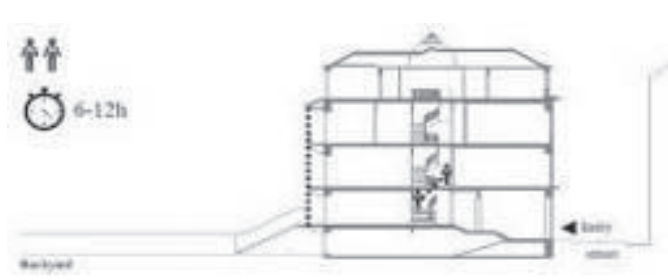

(a)

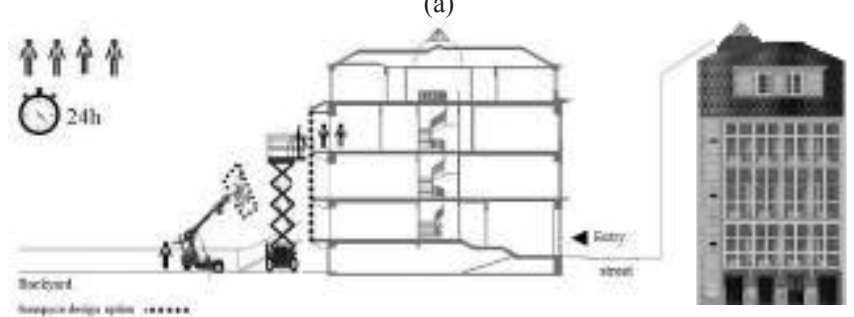

(b)

Figure 8. Installation comparison between membrane (a) and glazing (b) design options to close the case study building balconies.

\subsubsection{Maintenance}

To analyse the maintenance cost of the different solutions, there were assumptions and limitations to be made, Table 4. In particular, it was considered that PVC foil transparency and colour can change after several years in use and this can affect its durability. As so, the durability of building materials was taken into account on the maintenance/ replacement phase. For example, it was considered that PCV foil will be replaced twice in 60 years building life cycle. In a 60 years lifespan, when PVC foil is applied horizontally, it must be replaced each 15 years, while if it stands vertically the exposition to soiling and UV is reduced and the replacement can only be each 30 years. To increase durability of MAS 1, it was also considered that this could be retracted during summer periods, in order to reduce its exposure to climate variations, dusts and pollution, what would allow it to last the double of a fixed membrane. As it is retractable, its cleaning maintenance is easier than fixed solutions.

Glass solution can last almost eternally, so no change was considered in the lifespan, however it needs cleaning maintenance. A ten-year period was considered for exterior surface cleaning of glasses, frames and gaskets replacement.

Table 4. Considered aspects to perform economic and environmental life cycle evaluation of sunspace design options.

\begin{tabular}{|c|c|}
\hline Functional unity: & $1 \mathrm{~kg}$ of material \\
\hline Location: & Porto, Portugal \\
\hline $\begin{array}{l}\text { System boundary: } \\
\text { Calculation period: }\end{array}$ & $\begin{array}{l}\text { "cradle to the grave" } \\
\text { (without operation energy use phase) } \\
60 \text { years }\end{array}$ \\
\hline $\begin{array}{l}\text { Assumptions and lim } \\
\text { - The environmental } \\
\text { been assessed base } \\
\text { volume. } \\
\text { - It is considered tha } \\
\text { years; remaining } \mathrm{m} \\
\text { require periodic te } \\
\text { have been defined } \\
\text { solution. } \\
\text { - ETFE foil presents } \\
\text { by the rain; it rec } \\
\text { damage to be repa } \\
\text { Peters-plastic Gmbl } \\
\text { - Solutions ContS 1, } \\
\text { systems, are easily } \\
\text { and its recycling tyl } \\
\text { - Solutions TS, CS, } \\
\text { maintenance of the }\end{array}$ & $\begin{array}{l}\text { nitations: } \\
1 \text { impacts associated with transportation have } \\
\text { ed on the weight of materials, neglecting its } \\
\text { at the PVC membrane will be replaced after } 30 \\
\text { naterials will have a durability of } 60 \text { years but } \\
\text { en-year maintenance; maintenance operations } \\
\text { according installers recommendation of each } \\
\text { anti adhesive properties and it is self-cleaning } \\
\text { quires periodic inspections to detect possible } \\
\text { aired. ETFE foil recycling is documented by } \\
\text { H [9]. } \\
\text { ContS } 2 \text {, MAS } 1 \text { and MAS } 2 \text { are dry building } \\
\text { dismounted, all components can be separated } \\
\text { pe is down cycling. } \\
\text { ContS } 1 \text { and ContS } 2 \text { require periodic ten-year } \\
\text { sealing elements (rubbers) and glass cleaning. }\end{array}$ \\
\hline
\end{tabular}

\subsection{Economic aspects}

The comparative cost analysis (based on Table 3 and Table 4 considerations) presented on Table 5 shows that membrane solution MAS 1 is the most economical in terms of total construction and maintenance costs. It should be mentioned that: maintenance costs include cleaning scaffolds only for TS, CS and ContS 2 solutions; construction and maintenance costs values are estimated based on market suppliers and installer consulting and [9, 11]. Unlike other sunspace options, MAS 1 and MAS 2 options do not need auxiliary equipment to the 
construction and maintenance phases (as lifting equipment). MAS 2 has a higher construction cost than the equivalent reference solution ContS 1 and ContS 2, mainly because double ETFE encapsulated panels are still a recent product.

Table 5. Economic costs in a 60 years life span for the dwelling with $100 \mathrm{~m}^{2}$ sunspace design options.

\begin{tabular}{|lrrrr|}
\hline & $\begin{array}{r}\text { Construction } \\
\text { cost }(\boldsymbol{\epsilon})\end{array}$ & $\begin{array}{r}\text { Maintenance } \\
\text { cost }(\boldsymbol{\epsilon})\end{array}$ & $\begin{array}{r}\text { Total } \\
\text { Cost }(\boldsymbol{\epsilon})\end{array}$ & $\begin{array}{r}\text { Ranking } \\
(\mathbf{1 s t}=\text { best })\end{array}$ \\
\hline TS & 19500 & 3800 & 23300 & $4^{\circ}$ \\
\hline CS & 11500 & 2800 & 14300 & $\mathbf{2}^{\mathbf{0}}$ \\
\hline ContS 2 & 21440 & 2500 & 23940 & $5^{\circ}$ \\
ContS 1 & 21233 & 3000 & 26233 & $6^{\circ}$ \\
\hline MAS 1 & 7000 & 3500 & 10500 & $\mathbf{1}^{\circ}$ \\
MAS 2 & 21800 & 1090 & 22890 & $3^{\circ}$ \\
\hline
\end{tabular}

\subsection{Environmental aspects}

The six sunspace design options described before are analysed, considering a sixty years life cycle. Table 6 presents all the environmental parameters addressed from EN 15978 and the graphic at Figure 9 compares the Global Warming Potential (GWP) and Embodied Energy (EE) indicators for each design option (as it are the more impact ones). All environmental indicators were obtained from OneClick LCA [12] software and considering aspects of Table 4 .

Table 61. Environmental impact indicators for each design option, for a 60-year life cycle (obtained results with [12]).

\begin{tabular}{|c|c|c|c|c|c|c|}
\hline & TS & CS & ContS2 & ContS1 & MAS 1 & MAS 2 \\
\hline \begin{tabular}{|l|} 
GWP \\
$\left(\mathrm{kgCO}_{2} \mathrm{e}\right)$ \\
\end{tabular} & 8590 & 9266 & 7049 & 6664 & 3469 & 6374 \\
\hline$\% *$ & 60 & 31 & 51 & 48 & 0 & 46 \\
\hline \begin{tabular}{|l|}
$\mathrm{AP}$ \\
$\left(\mathrm{kgSO}_{2} \mathrm{e}\right)$ \\
\end{tabular} & 35 & 39 & 30 & 30 & 14 & 25 \\
\hline$\% *$ & 60 & 37 & 53 & 53 & 0 & 44 \\
\hline $\begin{array}{l}\mathbf{E P} \\
\left(\mathrm{kgPO}^{4} \mathrm{e}\right) \\
\end{array}$ & 18 & 8 & 8 & 10 & 5 & 6 \\
\hline$\%^{*}$ & 72 & 31 & 37 & 50 & 0 & 11 \\
\hline \begin{tabular}{|l|}
$\begin{array}{l}\text { ODP } \\
\text { (kgEthenee }\end{array}$ \\
\end{tabular} & 4 & 2 & 1 & 1 & 1 & 1 \\
\hline \%* & 76 & 55 & 0 & 0 & 0 & 0 \\
\hline \begin{tabular}{|l|l|}
$\mathbf{E E}$ \\
(MJ) \\
\end{tabular} & 105132 & 149229 & 110689 & 97123 & 75589 & 114232 \\
\hline$\% *$ & 28 & 23 & 32 & 22 & 0 & 34 \\
\hline \begin{tabular}{|l|} 
Ranking \\
(1st=best)
\end{tabular} & $6^{\text {th }}$ & $5^{\text {th }}$ & $4^{\text {th }}$ & $3^{\text {rd }}$ & $1^{\mathrm{st}}$ & $2^{\text {nd }}$ \\
\hline
\end{tabular}

Regarding Table 6 and Figure 9, it can be verified that: (1) MAS 1 and MAS 2 present lower environmental impacts and TS the higher ones;

(2) MAS 1 achieves a $11 \%$ to $76 \%$ environmental impact reduction;

(3) considering A1-A4 Construction materials phase, it is found that although the quantity of MAS 1 and MAS 2 materials is reduced, EE and GWP are high, mainly due to the chemical production process (of PVC and ETFE polymerization);

(4) ContS 1, ContS 2, MAS 1 and MAS 2 supporting structure is made of aluminium, which production involves large amounts of embodied energy; as the PVC or ETFE foil is much lighter than glass, these materials require a smaller supporting structure, reducing the amount of aluminium needed by $30 \%$ to $60 \%$, i.e. reducing the incorporated energy;

(5) Although MAS's weight is only $2 \%$ of the heaviest solution (CS) weight and $9 \%$ of the lighter reference one (ContS 2), since PVC or ETFE foils are produced in London, $2000 \mathrm{~km}$ distance from Porto city, while glass is produced in Portugal, $200 \mathrm{~km}$ distance from Porto city, $\mathrm{CO}_{2}$ emissions to carry MAS (transported by a 3.5-20t diesel motor vehicle) are practically the same to carry ContS 1 or ContS 2 solutions.

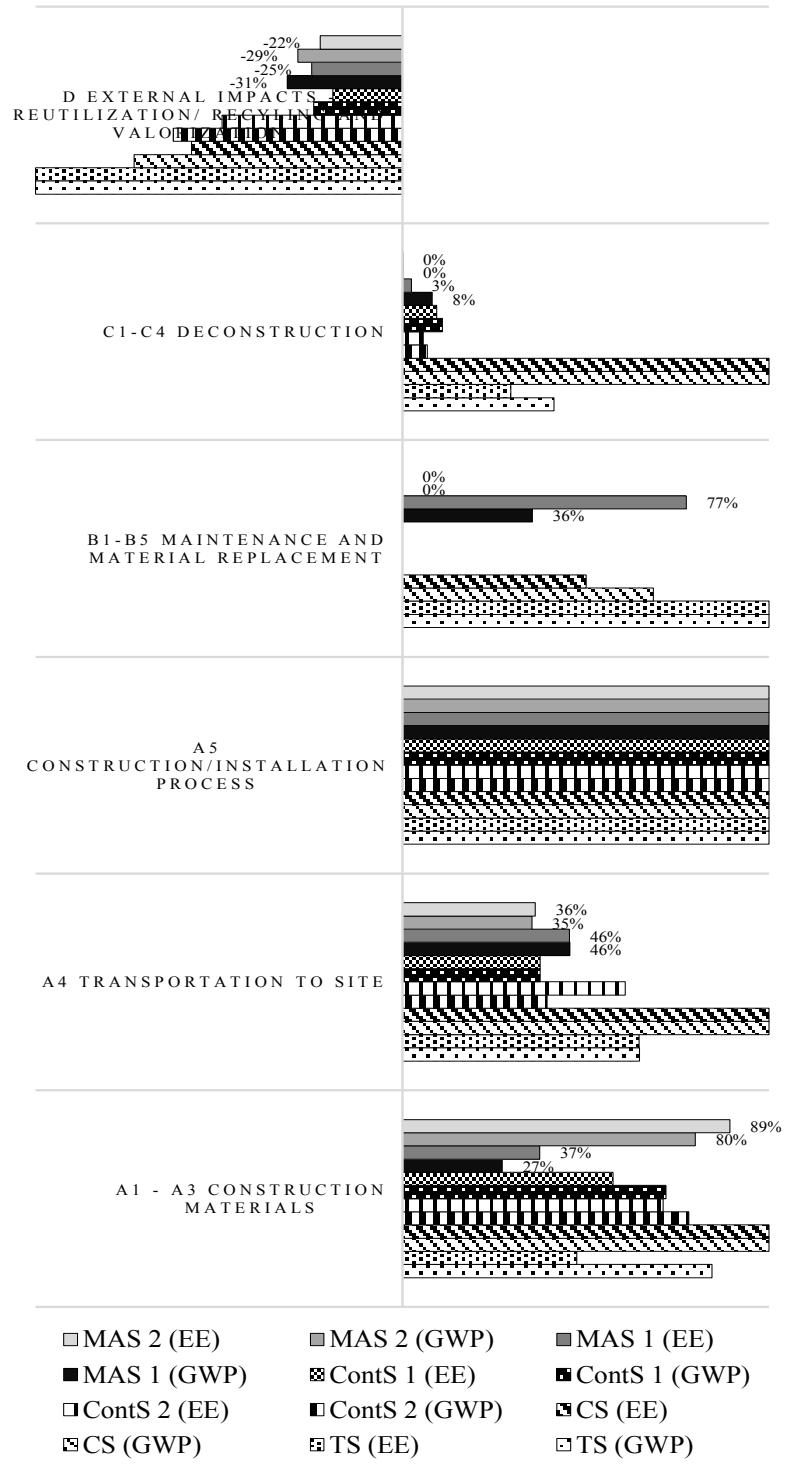

Figure 9. Life cycle phases comparison of all sunspace design options (GWP and EE indicators only).

Despite the replacement need of PVC foil, MAS 1 still presents lower environmental impact, mainly due to 
the fact that it has the smallest impact on end of life phase (C1-C4 module - deconstruction) and potential reuse/ recycling phase (D module). Instead, ETFE foil selfcleans (if it rains), avoiding the need for water, energy and cleaning products for its maintenance.

Regarding deconstruction phase, membrane solutions (MAS 1 and MAS 2) presents the lowest environmental impact as opposed to conventional (CS) and traditional (TS) solutions. In addition, energy saving from recycling rather than from new materials production is much higher in plastics $(88 \%)$ than in glass (only 5\%) [12] [14]. The low melting point of PVC makes the recycling process economical and with low environmental impact, while single glass consumes more energy in the recycling process and does not allow the reintroduction of material with the same quality (downcycling process) [7].

\section{Results - Global efficiency evaluation (used resources and obtained results relation)}

It should be noted that the present study focus only at constructive, economic and environmental aspects and do not consider the energy operational use phase.

Percentage radar graphs at Figure 10 show how the efficiency parameters under analysis are facing each other. In a global and comparative view of the various sunspace design options under evaluation, it is observed that the MAS are the most efficient ones; they are those that achieve the best results with a minimum amount of used resources, where MAS 1 stands out, especially in relation to "used resources". However MAS 1 presents worse "obtained results" compared to contemporary solutions, while MAS 2 overcomes this. In contrast, TS is the least efficient solution (Table 7).

In summary, overall, in a 60-year life-cycle scenario, membrane sunspace solutions are efficient alternatives (according to constructive, environmental and economic aspects) to traditional/ conventional/ contemporary ones to perform buildings functional refurbishment interventions, with architectural integration approach. In particular, MAS 1 exhibit lower weight and construction cost than the other solutions.

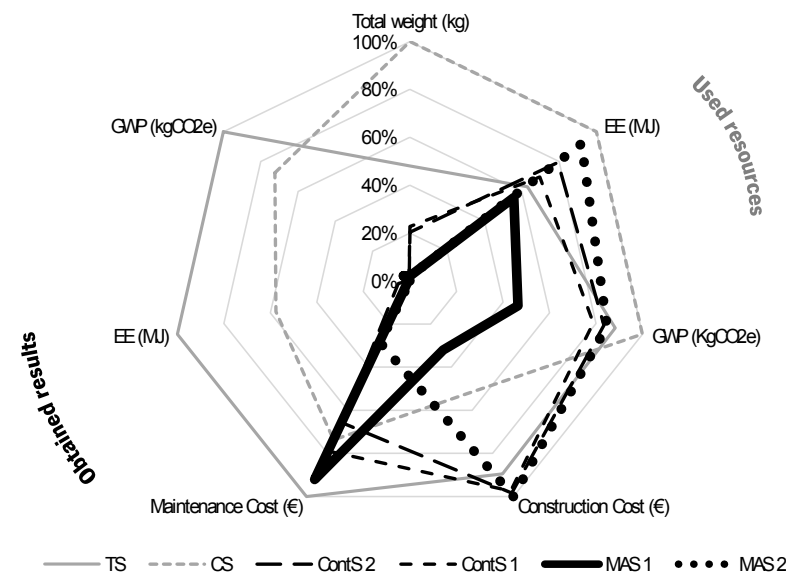

Figure 10. Sunspace design options comparison regarding used resources and obtained results relation. Evaluation of the efficiency considering that all aspects have equal weight in the final result: best $=0 \%$; worst $=100 \%$.

Table 7. Efficiency of the different solutions under analysis with respect to the MAS 1.

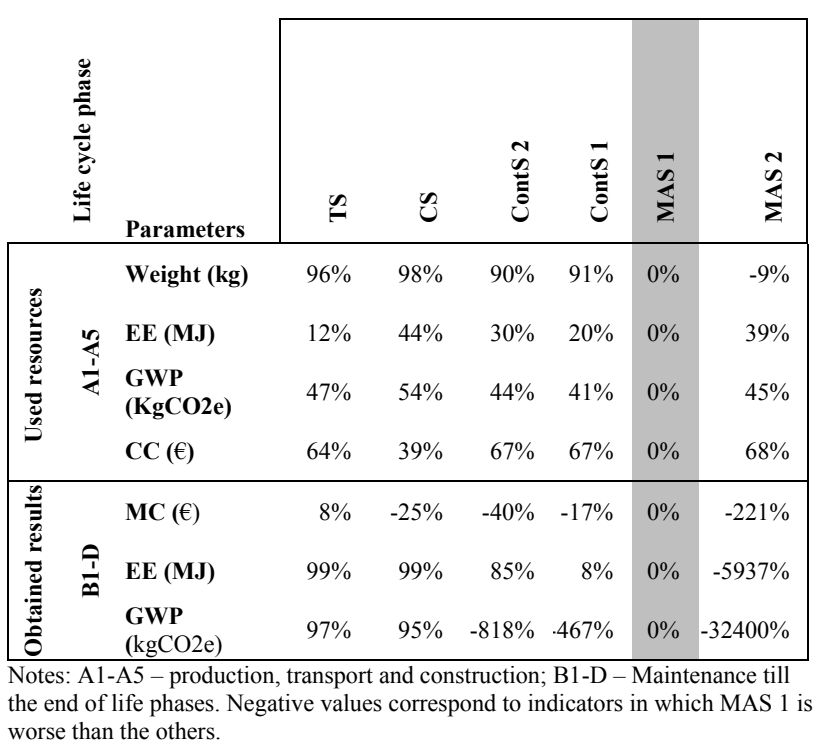

There are ongoing experimental tests on the MAS 1 full-scale prototype, to assess the building's hygrothermal performance when using this technology. This data will also allow calibrating a numerical model in order to compare this solution with identified common glazed solutions, when applied to this kind of buildings. Results, regarding hygrothermal comfort and operational energy consumption, will be included in future research.

\section{Conclusions}

The increasing importance given today to the environmental compatibility leads designers to combine both the use of energy efficient materials and technical solutions that try to maximize material savings. This research deals with architectural membranes, which are an example of this and that have recently been applied as vertical cladding systems to new constructions and retrofitted buildings. This paper explores the use of membranes for sunspace purposes, as a substitute for glass, the material that is commonly applied to this type of structures, overcoming its major weakness: its high weight and cost, associated particularly with the framing systems and accessories. For instance, the contemporary sunspace solution ContS 2 analysed in this paper, with a glass area of $100 \mathrm{~m}^{2}$ in the façade, needs $1631 \mathrm{~kg}$ of glass and $294 \mathrm{~kg}$ of aluminium, while the alternative membrane solution MAS 2 (e.g.) only uses $86 \mathrm{~kg}$ of ETFE membrane and $90 \mathrm{~kg}$ of aluminium structure.

The fact that membrane sunspace options requires less substructure, changes also the architectural approach; it gives more freedom to design options, with lower environmental impacts. However, it should be noted that membrane building solutions are not capable of replacing glass solutions in all intervention/ construction scenarios. 
They are interesting alternatives in cases where the use of glass is limited, especially for its size, weight and cost. In addition, membrane solutions also provide protection against material projection in case of seismic events, for example (unlike glass solutions).

The two alternative design options using membrane solutions that were analysed more in detail in this research, MAS 1 and 2, constitute passive solar systems that can be easily and profitably employed in buildings refurbishment. In particular, the results show that, even considering the periodical substitution of the material, due to its lower expected life, MAS 1 presents lower environmental impact indicators $(32 \%$ less than glass solutions in terms of total Embodied Energy) and reduced cost (almost $1 / 2$ of other design options). Notice that the energy consumption related to the operational phase was not considered in the environmental impact indicators on this paper. Nevertheless, it should be considered in future research.

In fact, MAS constitute efficient alternative sunspace solutions. MAS 1 and MAS 2 present an efficiency improvement, between $60 \%$ and $48 \%$, compared to the less efficient solution (TS), and between $19 \%$ and $7 \%$, compared to contemporary ones (ContS). Comparing now the two membrane solutions, MAS 1 (ranked $1^{\text {st }}$ ) presents lower durability. MAS 2 (ranked $2^{\text {nd }}$ ) overcomes this limitation, but still remains an efficient alternative to the other solutions (TS, CS and ContS 1/2).

In summary, membrane solutions allow buildings to be adapted and updated to the contemporary framework of sustainability. However, even with the increasing evolution that membrane materials achieved in the recent past, there is still a long way to go through, before they can be accepted and considered as sustainable, especially regarding social and cultural resistance when it involves housing. Therefore, more prototypes should be constructed and tested in order to increase knowledge and confidence on the use of membranes solutions.

\section{Acknowledgments}

First author thanks to FCT (Fundação para a Ciência e Tecnologia - Portugal), MCE (Ministério da Educação e Ciência - Portugal) and ESF (European Social Fund) for supporting the research fellowship with the reference SFRH/BD/104891/2014; and with other authors thanks the financial support from the Project UID/AUR/04509/2013 by FCTMEC by national funding and, when applicable, FEDER co-financing under the new PT2020 partnership agreement - Lab2PT, School of Architecture/ University of Minho, Portugal and Project POCI-01-0145-FEDER-007457 - CONSTRUCT Institute of $R \& D$ In Structures and Construction of Faculty of Engineering/ University of Porto, Portugal, funded by FEDER funds through COMPETE2020.

Authors also thanks to: owners of the building case study, that allow the MAS1 full-scale prototype integration on it; and Floret architecture firm that provides case study building designs. Also thanks to Bionova Ltd for provide a One Click LCA student license.

\section{References}

1. M. Macieira, P. Mendonça, J. M. Guedes, "Architectural membranes on building's functional refurbishment" in ICBMM 2017; IOP Publishing; IOP Conf. Series: Materials Science and Engineering $264 \quad 012005$ doi:10.1088/1757899X/264/1/012005, (2017).

2. P. Mendonça, "Living under a second skin Environmental Impact reduction strategies of solar passive buildings in temperate climates", University of Minho: Guimarães, (2005).

3. D. Aelenei, H. Azevedo Leal, L.Aelenei; "The use of Attached-sunspaces in retrofitting design: the case of residential buildings in Portugal"; Proceedings of the 2nd International Conference on solar Heating and Cooling for Buildings and Industry (SHC 2013 Energy Procedia (48) - p.1436-1441), (2013).

4. K. Hilliaho, "Energy Saving Potential and Interior Temperatures of Glazed Spaces: Evaluation through Measurements and Simulations", Doctoral dissertation, Tampere University of Technology, Finland (2017).

5. J. Mattila, "Balcony glazing protects the building structures". Available from: http://okostyle.spb.ru/content/files/balkony-I.pdf (2002).

6. H. Gonçalves, M. Oliveira, A. Patricio, P. Cabrito, "Passive Solar Buildings in Portugal - Experiences in the Last 20 Years, Proceedings of PLEA' 98. James \& James Science Publishers Ltd: Lisbon, Portugal, (1998).

7. P. Mendonça, "Low-span lightweight membranes in housing - environmental and structural potentialities", Structures and Architecture. Cruz (Ed.), Taylor \& Francis Group, London (2010).

8. Holscot Fluoroplastics Ltd., "ETFE panels"; available from: http://holscot.com/products/etfepanels/, accessed on: 18/05/2017

9. Cype, "Prices generator software" (in Portuguese). Available from: http://www.geradordeprecos.info/; accessed on 15/06/2017.

10. Texlon, "Environmental Product Declaration Texlon ${ }^{\circledR}$ system", EPD-VND-2011111-E, Vector Foiltec - Nowofol - Dyneon, Institut Bauen und Umwelt, www.bau-umwelt.com, October (2011).

11. A. Manso, M. Fonseca, J. Espada, "Informação sobre Custos. Fichas de Rendimentos", Laboratório Nacional de Engenharia Civil: Lisbon (2004).

12. One Click LCA (C) copyright Bionova Ltd/Version: 20.12.2017, database version: 7.3, Helsinki: Bionova Ltd (2017).

13. T. Mumma "Reducing Embodied Energy of Building", Home Energy Magazine, January/ February (1995).

14. J. Knippers, J. Cremers, M. Gabler, J. Lienhard, «Construction Manual for Polymers +Membranes»; Birkhäuser GmbH, Basel

(2011) 